\title{
VARIABILIDADE ESPACIAL E CONTROLE ESTATÍSTICO DO PROCESSO DE PERDAS NA COLHEITA MECANIZADA DO ALGODOEIRO
}

\author{
ROUVERSON P. SILVA ${ }^{1}$, FÁBIO G. SOUZA ${ }^{2}$, JORGE W. CORTEZ ${ }^{3}$, \\ CARLOS E. A. FURLANI ${ }^{4}$, GUSTAVO P. VIGNA ${ }^{5}$
}

\begin{abstract}
RESUMO: Dentro do processo produtivo, a colheita, se mal conduzida, poderá causar prejuízos quali-quantitativos no produto final. Dessa forma, esse trabalho teve o objetivo de avaliar as perdas quantitativas, no solo e na planta, na colheita mecanizada de algodão, no ano agrícola de 2006, em Ipameri-GO, em um talhão de 1,4 ha, sendo georreferenciados 41 pontos, distanciados de $50 \mathrm{~m}$ no sentido da curva de nível e $9 \mathrm{~m}$ entre fileiras. As amostras foram coletadas colocando-se uma armação de $4,5 \mathrm{~m}^{2}$ sobre o solo, coletando todo o algodão caído no solo e, em seguida, fez-se a coleta do algodão que permaneceu na planta após a passagem da colhedora. Além das perdas quantitativas determinaram-se o teor médio de água do algodão e o Rendimento Potencial Máximo (RPM). Foram construídas cartas de controle para verificar a qualidade da operação de colheita. Observou-se que as perdas na colheita do algodão foram altas, principalmente as perdas no solo (PS), indicando que a colhedora não apresentou boa eficiência de colheita. As perdas no solo não apresentaram dependência espacial, enquanto as perdas na planta e totais apresentaram dependência moderada e forte, respectivamente. O processo de colheita de algodão não se encontra dentro dos padrões de qualidade, sob o ponto de vista de controle estatístico de processo, devendo ser revistas as condições de colheita.
\end{abstract}

PALAVRAS-CHAVE: agricultura de precisão, colhedora de algodão, geoestatística.

\section{SPATIAL VARIABILITY AND STATISTICAL CONTROL PROCESS OF LOSSES IN THE MECHANIZED HARVESTING OF COTTON}

\begin{abstract}
The harvest is a very important stage of the productive process and in recklessness case; the final product can be influenced in significant way, causing quantitative and qualitative damages in the final item. In such way, this work had the objective to evaluate the cotton harvesting losses, in the soil and the plant, in the agricultural year of 2006, in Ipameri-GO. The work was carried through in an area of 1.44 ha, being demarcated 64 points, distanced of $50 \mathrm{~m}$ in the direction of the curve of level and $9 \mathrm{~m}$ between rows. The showed points had been georeferenced with aid of a GPS Garmin registering itself the coordinates in UTM. The samples had been collected placing a scaffolding of $4.5 \mathrm{~m}^{2}(4.5 \times 1 \mathrm{~m})$ on the cotton plants, collecting all the cotton fallen in the soil and after that. Beyond the quantitative losses analysis, it was determined the moisture content and productivity. The samples to determine the water text had been removed directly in the "Bass Boy" (overflow) in four different points. It was observed that the losses in the harvest of the cotton had been high, mainly the losses in the soil (PS), indicating that the harvester did not present good efficiency of harvest. The losses in the soil had not presented spatial dependence, whereas the losses in the plant and total had presented moderate and strong dependence respectively.
\end{abstract}

KEYWORDS: precision farming, cotton harvester, geostatistics.

\footnotetext{
${ }^{1}$ Eng ${ }^{\mathrm{o}}$ Agrí́cola, Prof. Assistente Dr., Departamento de Engenharia Rural, UNESP/Jaboticabal, Via de Acesso Prof. Paulo Donato Castellane, km 5, Jaboticabal - SP, rouverson@ fcav.unesp.br. Bolsista de Produtividade em Pesquisa - CNPq.

${ }^{2}$ Eng $^{\mathrm{o}}$ Agrônomo, Departamento de Engenharia Rural, UNESP/Jaboticabal - SP.

${ }^{3}$ Eng $^{0}$ Agrônomo, Pós-Graduando em Agronomia (Produção Vegetal), UNESP/Jaboticabal - SP. Bolsista CAPES.

${ }^{4}$ Eng $^{\mathrm{o}}$ Agrônomo, Prof. Adjunto, Departamento de Engenharia Rural, UNESP/Jaboticabal - SP. Bolsista de Produtividade em Pesquisa - CNPq.

${ }^{5}$ Acadêmico do curso de Agronomia, UNESP/Jaboticabal - SP.

Recebido pelo Conselho Editorial em: 15-3-2007
}

Aprovado pelo Conselho Editorial em: 24-10-2007 


\section{INTRODUÇÃO}

As transformações ocorridas na agricultura brasileira foram profundas, principalmente com a cultura do algodoeiro que, em pouco tempo, passou de cultura familiar, com forte demanda de mãode-obra, para produção em grande escala com vultosos investimentos de capital e alta tecnologia, principalmente nos cerrados da região Centro-Oeste. Uma etapa de muita importância dentro do processo produtivo do algodão é a colheita e, quando realizada de forma inadequada, pode acarretar prejuízos quantitativos e qualitativos no produto final (ELEUTÉRIO, 2001).

A necessidade de realizar a colheita no menor tempo possível, devido, principalmente, à ocorrência de fatores climáticos adversos, pode acarretar o aumento das perdas na colheita, que devem ser sempre monitoradas em busca de sua minimização.

Dentro desse contexto, deve-se atentar para as perdas na colheita, que devem ser monitoradas com o objetivo de detectar os erros que podem ocorrer durante o processo, e para que os mesmos possam ser corrigidos.

De acordo com a EMBRAPA (2001), a colheita mecânica é recomendada em regiões onde a colheita manual não é viável, quer seja pelo baixo rendimento, quer seja pelo maior custo.

Segundo a EMBRAPA (2006), a colheita do algodão em caroço é de grande importância para a qualidade global do produto final; por isso, deve ser realizada no tempo certo e com todo cuidado, sendo importante, em virtude do seu hábito de crescimento, indeterminado, colher o máximo de algodão, seja por meio da colheita mecânica, seja da colheita manual, sem que haja prejuízo tanto no tipo quanto na qualidade do produto colhido. Sabe-se que a qualidade final da semente e da fibra do algodoeiro depende da tecnologia de pré-colheita, colheita e pós-colheita. Nesse aspecto, é importante salientar que os métodos empregados nas duas últimas fases são fundamentais para a qualidade, assim como deles também depende o tempo de armazenamento, importante na comercialização do produto.

Para a colheita da cultura do algodoeiro, existem dois tipos de máquinas: a colhedora de fusos (spindles), que retira apenas o algodão em caroço e a colhedora stripper, dotada de sistema de roldanas, que retira capulhos inteiros e os invólucros (EMBRAPA, 2006).

As perdas na colheita de algodão ocorrem em função dos mais variados problemas, dentre os quais se destacam: ponto de maturação, condições de colheita, regulagens de máquinas, velocidade de colheita, porte da planta, tipo de máquina, tipo de solo, variedade e fatores climáticos (OOSTERHUIS, 1999). A colheita mecânica de qualquer tipo, embora seja sempre mais rápida que a manual, sofre perdas de produto bem maiores que essa, com perdas na ordem de 15 a $17 \%$ na colheita mecânica e de apenas 5\%, na manual. Além das perdas, o rendimento no beneficiamento é bem menor na colheita mecânica, devido à quantidade de impurezas que levam. As perdas qualitativas ocorrem na ordem de $35 \%$ para o algodão colhido mecanicamente e de $5 \%$ para o colhido manualmente (EMBRAPA, 2006). Seguindo critérios mais rigorosos, VIEIRA et al. (2001) referem-se a $10 \%$ de perdas como sendo o máximo aceitável na colheita mecânica, com faixa ideal situada entre 6 e $8 \%$. Fatores no manejo cultural, tais como a população de plantas e a velocidade de operação das máquinas, bem como os treinamentos dos operadores podem influenciar de forma positiva e eficiente na redução das perdas na colheita mecanizada.

De acordo com RIBEIRO JÚNIOR (1995), a geoestatística consta de um conjunto de métodos e conceitos estatísticos, utilizados para a compreensão e modelagem da variabilidade espacial de fenômenos, quando as informações coletadas são georreferenciáveis e apresentam dependência espacial. Na análise espacial, considera-se que os valores amostrais são realizações de funções casuais e que o valor de um ponto é função da sua posição no espaço, considerando-se também a posição relativa dos pontos amostrados.

O semivariograma é definido como o gráfico da função semivariância dada na forma geral como $\gamma(h)=1 / 2 \mathrm{E}[\mathrm{Z}(\mathrm{s}+h)-\mathrm{Z}(\mathrm{s})]^{2}$ versus a distância $h$, em que $Z(s)$ é uma variável regionalizada (conhecida na bibliografia como função aleatória ou processo estocástico) na posição $s$, sendo $s$ a 
coordenada $\left(x i, y j\right.$ ) de um espaço euclidiano $\mathrm{S} \subset \mathrm{R}^{2}$. Assim, o semivariograma é um procedimento utilizado para medir a dependência entre pontos amostrais separados pela distância $h$, distribuídos em um sistema espacial de referência.

Nos semivariogramas, a anisotropia pode ser facilmente constatada por meio da observação dos semivariogramas obtidos para diferentes direções, assim os semivariogramas, por exemplo, obtidos para as direções $0^{\circ} ; 45^{\circ} ; 90^{\circ}$ e $135^{\circ}$, e existe uma similaridade entre eles; essa representação é um caso simples, em que a distribuição espacial do fenômeno é denominada isotrópica. Desse modo, um único modelo é suficiente para descrever a variabilidade espacial do fenômeno em estudo. Por outro lado, se os semivariogramas não são iguais em todas as direções, a distribuição é denominada anisotrópica (CAMARGO, 2007). No semivariograma, o efeito pepita indica a variabilidade não-explicada, que pode ocorrer devido aos erros de medidas e microvariação. Quando o semivariograma for constante, o efeito pepita será igual ao patamar, para qualquer valor de $h$, obtendo-se o efeito pepita puro ou ausência total de dependência espacial, o que significa que o alcance (Ao), para os dados em questão, é menor do que o menor espaçamento entre amostras, apresentando distribuição completamente aleatória (FREDDI, 2003). LANDIM (1998) definiu um parâmetro de comparação do tamanho do efeito pepita, propondo o Avaliador da Dependência Espacial (ADE), dado pela eq.(1).

$$
\mathrm{ADE}=\frac{\mathrm{C}}{\mathrm{C}+\mathrm{Co}} 100
$$

em que,

C - variância estrutural, e

C + Co - variância do patamar.

Para LANDIM (1998), quando ADE < 25\%, a correlação é considerada fraca; ADE entre 25 e $75 \%$ é moderada, e ADE $>75 \%$ possui forte correlação.

Não há consenso, na bibliografia, a respeito do número mínimo de pares de pontos amostrais suficientes para a estimativa da semivariância experimental a cada "lag." WOLLENHAUPT et al. (1997) afirmam que se deve utilizar o mínimo de 30 pares, enquanto WEBSTER \& OLIVER (1990) recomendam o mínimo de 100 pares de pontos amostrais.

A verificação do ajuste adequado de um modelo pode ser realizada por meio da validação cruzada, retirando informações do conjunto original de dados e estimando-os a partir do restante dos pontos. Segundo ROBERTSON (1998), para um ajuste perfeito, a validação deve apresentar-se com coeficiente linear igual a zero e coeficiente angular igual a 1.

Segundo MILAN (1997), a sobrevivência das empresas agrícolas está intimamente ligada à implantação de novas técnicas administrativas com enfoque no controle estatístico de processos (CEP) e, principalmente, as novas maneiras de pensar.

O controle de qualidade é perfeitamente adaptável ao sistema de produção agrícola; sabe-se que, com a correção e a eliminação de desperdícios e falhas, redução de custos e aumento da produtividade, inúmeras vantagens serão acrescidas à competitividade do campo (BONILLA, 1994). De acordo com KUME (1993) e MONTGOMERY (1985), a carta de controle é uma das principais ferramentas utilizadas no controle estatístico da qualidade.

Pressupondo-se que as perdas na colheita mecanizada apresentem dependência espacial, que os pontos amostrados possam interferir nos valores obtidos, o uso das cartas de controle pode ser indicativo de como estão as perdas em determinada área, realizou-se o presente trabalho visando a avaliar as perdas quantitativas na cultura do algodoeiro no momento da colheita. 


\section{MATERIAL E MÉTODOS}

O trabalho foi realizado em um talhão de 1,4 ha, sendo demarcados 41 pontos, distanciados de $50 \mathrm{~m}$ na direção da curva de nível e $9 \mathrm{~m}$ entre fileiras, resultando em malha irregular, conforme apresentado na Figura 1. Os pontos amostrados foram georreferenciados com auxílio de um aparelho de GPS Garmin (precisão de 1 a 10 m), registrando-se as coordenadas em UTM (sistema de coordenadas em metros).

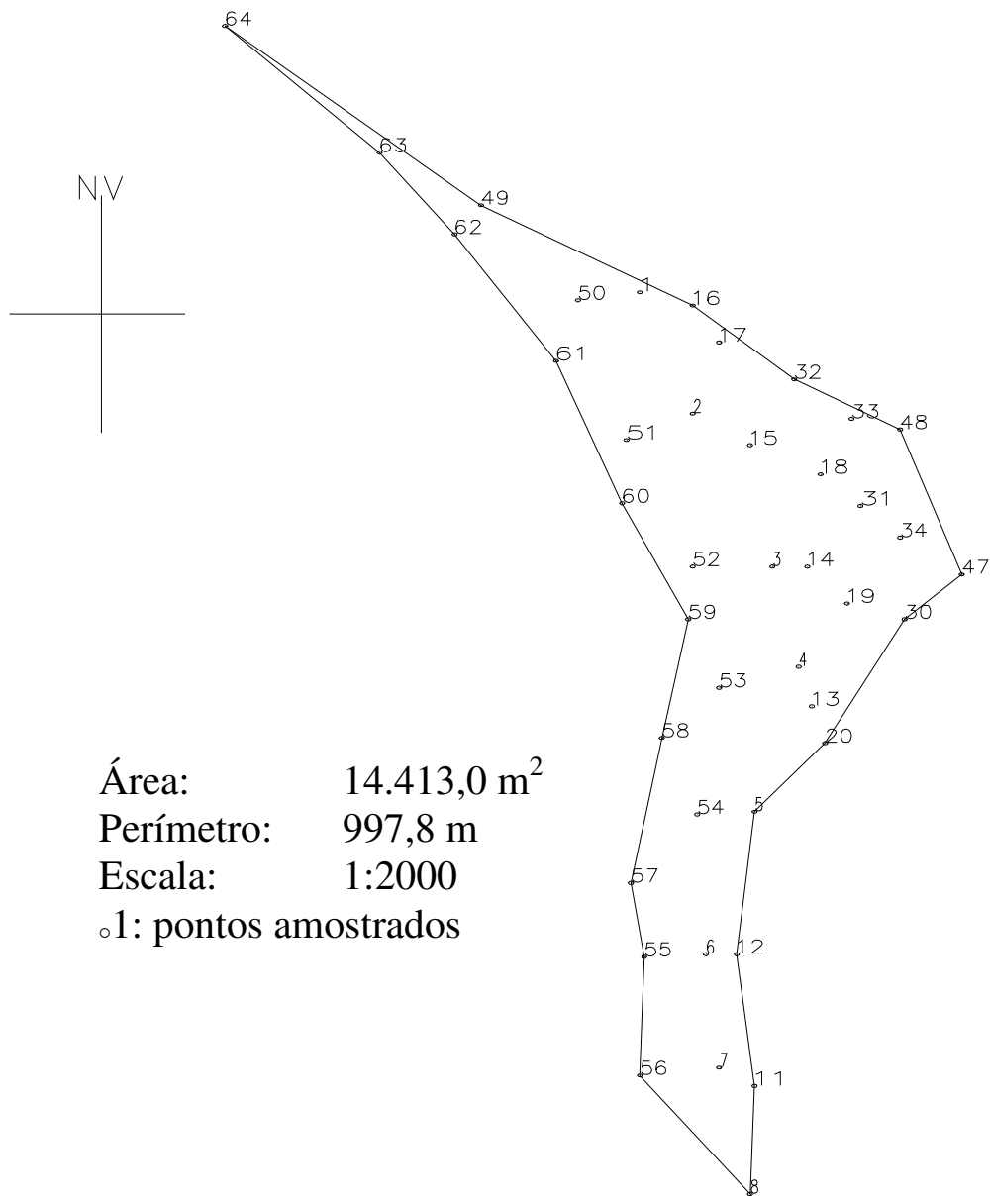

FIGURA 1. Croqui da área amostrada para a determinação das perdas na colheita mecanizada de algodão.

A colheita foi realizada na Fazenda Santo Antônio, em Ipameri - GO, localizada nas coordenadas geográficas: latitude $15^{\circ} 43^{\prime} \mathrm{S}$ e longitude $47^{\circ} 50^{\prime} \mathrm{W}$, com altitude média de $837 \mathrm{~m}$, declividade média de $1,5 \%$ e clima Cwa (subtropical), de acordo com a classificação de Köeppen, e a cultivar de algodão colhida foi o Delta Opal, com espaçamento entre fileiras de $0,90 \mathrm{~m}$. A colheita foi realizada com máquina própria, sendo a cultura monitorada por técnicos da Fundação Goiás para o controle de pragas e doenças.

A colheita foi realizada em agosto de 2006, utilizando-se de uma colhedora marca John Deere, modelo 9960, do tipo spindles, com potência de $186 \mathrm{~kW}(253 \mathrm{cv})$, equipada com plataforma de cinco linhas, de $4,5 \mathrm{~m}$ de largura e velocidade de $5,8 \mathrm{~km} \mathrm{~h}^{-1}$, considerada adequada para a colheita mecanizada de algodão que, de acordo com BRUNETA (2005), deve ser de, no máximo, $6 \mathrm{~km} \mathrm{~h}^{-1}$. Essa velocidade, próxima desse limite, foi utilizada na propriedade em virtude de alguns problemas ocorridos no período de colheita, tais como a ocorrência de chuvas, dias antes da colheita, e problemas mecânicos na plataforma de colheita, o que fez com que a colhedora ficasse parada para manutenção por aproximadamente dois dias.

Em cada ponto da malha, foi realizada a amostragem para a determinação das perdas, utilizando-se de armação de 4,5 $\mathrm{m}^{2}$ (4,5 x 1,0 m). A amostragem foi realizada em duas etapas, 
sendo a primeira realizada anteriormente à colheita, para estimativa do Rendimento Potencial Máximo (RPM), coletando-se manualmente todo o algodão presente nas plantas, em $5 \mathrm{~m}$ de uma fileira, totalizando quatro amostras com $4,5 \mathrm{~m}^{2}$ (considerando espaçamento de $0,90 \mathrm{~m}$ entre fileiras). Ainda na primeira etapa, foi realizada a coleta para a determinação do teor de água do algodão, retirando-se quatro amostras de aproximadamente $400 \mathrm{~g}$, no momento de descarga do algodão colhido para o transbordo (Bass Boy). Também, na primeira etapa, avaliou-se a perda natural, constatando-se que a mesma foi desprezível, não sendo portando considerada neste trabalho.

Na segunda fase, foi realizada a colheita, coletando-se os dados para a estimativa de perdas no solo (PS), na planta (PP) e perdas totais (PT). As coletas referentes às perdas no solo foram feitas colocando-se a armação no solo e coletando manualmente todo algodão caído na superfície. Na mesma área de coleta das perdas no solo, foi realizada a coleta para a estimativa de perdas na planta, arrancando-se manualmente todo o algodão que permaneceu na planta após a passagem da colhedora. Todas as amostras foram colocadas em sacos de papel devidamente numerados, que posteriormente foram pesados em laboratório. Para a determinação das perdas totais, procedeu-se à soma dos resultados obtidos para as perdas no solo e na planta.

Para permitir a visualização geral do comportamento dos dados, procedeu-se, inicialmente, à análise descritiva, utilizando-se do programa Minitab ${ }^{\circledR}$ para o cálculo das medidas de tendência central (média aritmética e mediana), das medidas de dispersão (valores máximo e mínimo, desviopadrão e coeficiente de variação) e das medidas de assimetria e de curtose. Efetuou-se, também, o teste de Anderson-Darling para caracterizar a normalidade dos dados (VIEIRA et al., 2002).

Para a verificação da dependência espacial das variáveis, interpolação dos dados e construção de mapas de isolinhas, empregou-se a análise geoestatística, conforme recomendado por VIEIRA (2000). Foram construídos semivariogramas, por meio do programa computacional Gs ${ }^{+\circledast}$, ajustados pelo maior valor do coeficiente de determinação $\left(\mathrm{r}^{2}\right)$, menor valor da soma de quadrados dos desvios (RSS) e maior grau de dependência espacial (ADE).

O ajuste do semivariograma foi realizado "a sentimento", escolhendo-se um modelo e seus parâmetros, sobrepondo-o aos pontos estimados e verificando-se visualmente sua adequação. $\mathrm{O}$ processo se repetiu até que fosse encontrado um bom modelo, que foi então posto à prova por meio da validação cruzada.

Por meio de interpolação por krigagem, utilizando-se do programa computacional do Surfer ${ }^{\circledR} 7.0$, foram obtidos os mapas de isolinhas (bidimensionais) para o detalhamento espacial dos atributos, permitindo, assim, visualizar as áreas que apresentassem variabilidade espacial. De acordo com SILVA \& CHAVES (2001), essa visualização pode ser realizada mediante o uso de mapas de isolinhas obtidos por meio da interpolação dos dados, pelo método de krigagem; nesses mapas, linhas fechadas e próximas caracterizam áreas com maior variabilidade, enquanto linhas espaçadas refletem menor condição de variabilidade.

Para o controle estatístico de processos (CEP), foram avaliadas as perdas no solo, na planta e totais. Os métodos estatísticos utilizados em ambas as fases foram as cartas de controle pela média. As convenções utilizadas na carta de controle são descritas como LIC e LSC, limites inferior e superior de controle, respectivamente, determinados estatisticamente, a partir da média e do desviopadrão das amostras, de acordo com as eqs.(2), (3) e (4).

$$
\begin{aligned}
& \mathrm{LM}=\mu \\
& \mathrm{LIC}=\mu-3 \frac{\sigma}{\mathrm{c}_{2} \sqrt{\mathrm{n}}} \\
& \mathrm{LSC}=\mu+3 \frac{\sigma}{\mathrm{c}_{2} \sqrt{\mathrm{n}}}
\end{aligned}
$$

em que, 
LM - linha média;

$\mu$ - média das médias dos subgrupos;

LIC - limite inferior de controle;

$\sigma$ - desvio-padrão médio;

$\mathrm{c}_{2}$ - fator de ajuste à distribuição normal;

n - tamanho da amostra, e

LSC - limite superior de controle.

\section{RESULTADOS E DISCUSSÃO}

O Rendimento Potencial Máximo na área foi de $2.925 \mathrm{~kg} \mathrm{ha}^{-1}$, e o teor médio de água no momento da colheita foi de $11 \%$. Na Tabela 1, são apresentados os parâmetros da estatística descritiva das perdas no solo, na planta e totais para a cultura do algodão. Observa-se que as médias de perdas foram muito altas, correspondendo a 11,4; 5,3 e 16,7\%, para as perdas no solo, na planta e totais, respectivamente. Nas condições de cerrado, como é o caso da área em questão, as perdas totais situam-se entre 9,4\% (NOGUEIRA \& SILVA, 1993) e 12,5\% (FREIRE et al., 1995). É interessante notar que as perdas no solo foram bem maiores do que as perdas na planta, indicando que a ação de recolhimento da colhedora não foi eficiente o bastante para proporcionar a completa colheita do algodão. Comparando-se as perdas encontradas no solo com os valores aceitáveis apresentados na bibliografia, nota-se que somente essas perdas foram suficientes para alcançar o limite tolerável.

TABELA 1. Estatística descritiva dos atributos das perdas na colheita de algodão no solo (PS), na planta (PP) e total (PT).

\begin{tabular}{lrrr}
\hline \multirow{2}{*}{ Parâmetros } & \multicolumn{3}{c}{ Perdas $\left(\mathrm{kg} \mathrm{ha}^{-1}\right)$} \\
\cline { 2 - 4 } & PS & PP & PT \\
\hline Média & 334,5 & 154,5 & 489,0 \\
Mediana & 334,5 & 150,0 & 480,0 \\
Desvio-padrão & 108,0 & 69,0 & 120,0 \\
Erro-padrão & 16,5 & 10,5 & 19,5 \\
Variância & 771,0 & 321,0 & 978,0 \\
Mínimo & 141,0 & 27,0 & 255,0 \\
Máximo & 574,5 & 336,0 & 744,0 \\
Cs & 0,4 & 0,9 & 0,2 \\
Ck & $-4,2$ & 1,0 & $-0,6$ \\
C.V. $(\%)$ & 32,1 & 44,9 & 24,7 \\
\hline
\end{tabular}

C.V. - coeficiente de variação; Cs - coeficiente de assimetria; Ck - coeficiente de curtose.

Em razão da existência de poucos trabalhos sobre perdas na colheita de algodão, pode-se explicar as perdas encontradas traçando paralelo com as perdas de outras culturas. MESQUITA et al. (2001) e CAMPOS et al. (2005) explicam que, para evitar parcialmente as perdas na colheita de soja, uma série de cuidados devem ser tomados, tais como: monitoramento da velocidade de trabalho da colhedora e das regulagens dos sistemas de limpeza e de separação, além de considerar o tempo de uso da máquina e o treinamento dos operadores, pois esses fatores diminuem o rendimento da colhedora.

$\mathrm{O}$ alto índice de perdas encontrado pode ainda ser explicado pelo fato de que, no momento da colheita, havia grande número de maçãs que não se encontravam abertas devido à ação de pragas, principalmente o bicudo do algodoeiro (Anthonomus grandis), levando-se em consideração os sintomas observados. Esse alto número de maçãs não abertas fez com que o fluxo de entrada de algodão na máquina fosse reduzido, diminuindo a eficiência da colhedora, o que refletiu no aumento das perdas no momento da colheita. 
Ainda na Tabela 1, observa-se que, segundo os critérios apresentados por WARRICK \& NIELSEN (1980), os valores dos coeficientes de variação (C.V.) foram altos (>24\%), indicando que nos pontos nos quais foram amostradas as perdas, os valores observados encontravam-se afastados da média. Os valores altos de C.V. indicam a grande variabilidade das perdas em função do local amostrado. Pode-se compreender melhor esse fato examinando-se os valores de mínimo e máximo, muito distantes entre si. Os índices de assimetria (Cs) e de curtose $(\mathrm{Ck})$ próximos de zero, exceto para a variável PS, indicam a simetria da distribuição. GUIMARÃES (2001) afirma que, nos programas Excel $^{\circledR}, \mathrm{SAS}^{\circledR}$ e Gs ${ }^{\circledR}$, o valor de $\mathrm{Ck}$ e Cs para que ocorra distribuição normal, deve ser igual a zero para ambos.

Para ajuste dos semivariogramas, foi escolhido o modelo isotrópico que, se por um lado detalha menos a estrutura espacial de correlações, por outro é mais simples, uma vez que possui menor número de parâmetros (RIBEIRO JÚNIOR, 1995). Os parâmetros dos semivariogramas ajustados e os mapas de isolinhas são apresentados na Tabela 2 e nas Figuras 2 e 3 , respectivamente.

As perdas no solo (PS) não apresentaram dependência espacial, evidenciando a dificuldade de se chegar a um ajuste devido à forte tendência para atingir o efeito pepita puro ou a ausência total de dependência espacial para essa variável (EGUCHI et al., 2002). Segundo MELLO \& CATANEO (2001), a independência espacial pode ocorrer devido à adoção de espaçamento de amostragem grande, quando deveria ter-se adotado menor espaçamento para que houvesse possibilidade de revelar a dependência espacial. SILVA \& CHAVES (2001) afirmam que, quando ocorre ajuste menos restritivo, pode ocorrer de os valores serem adequados ao modelo tipo efeito pepita puro, o qual garante a total aleatoriedade dos dados, ou seja, que a média correspondente a esses dados pode ser usada para descrever o seu comportamento. De acordo com CAMARGO (2007), quando o semivariograma apresenta efeito pepita puro, ou não se consegue ajustar um modelo, isso pode ser atribuído ao erro de amostragem, ou ao espaçamento de amostragem nãoadequado para representar a variabilidade dessa variável. Outro fator que pode ser o causador em se chegar ao ajuste é a variação da microescala, pois dentro da malha de amostragem faz-se necessário realizar subdivisão do grid em tamanhos menores para que se possa verificar a variabilidade em espaçamentos menores.

Para a variável perdas na planta (Tabela 2), o semivariograma ajustado foi exponencial, com dependência espacial moderada, enquanto, para a variável perdas totais, ajustou-se o modelo esférico, com forte dependência espacial, resultados que são concordantes com LANDIM (1998).

O valor de alcance obtido para perdas no solo foi de $8,2 \mathrm{~m}$, enquanto, para as perdas totais, foi de $21,3 \mathrm{~m}$.

TABELA 2. Parâmetros dos semivariogramas ajustados aos atributos das perdas na colheita do algodão no solo, na planta (PP) e totais (PT).

\begin{tabular}{lcccccccc}
\hline & \multicolumn{7}{c}{ Parâmetros dos Semivariogramas } \\
\cline { 2 - 8 } Tipo & Modelo & $\begin{array}{c}\text { Efeito } \\
\text { Pepita } \\
(\mathrm{Co})\end{array}$ & $\begin{array}{c}\text { Patamar } \\
(\mathrm{Co}+\mathrm{C})\end{array}$ & $\begin{array}{c}\text { Alcance } \\
(\mathrm{m})\end{array}$ & $\mathrm{r}^{2(\mathrm{a})}$ & $\mathrm{SQR}^{(\mathrm{b})}$ & $\mathrm{ADE}^{(\mathrm{c})}$ & Classe \\
\hline PP & Exponencial & 4,5 & 17,6 & 8,2 & 0,1 & 26,0 & 74,6 & $\begin{array}{c}\text { moderada } \\
\text { PT }\end{array}$ \\
\hline
\end{tabular}

(a) $\mathrm{r}^{2}$ - coeficiente de determinação; (b) SQR - soma dos quadrados dos desvios; (c) ADE - avaliador da dependência espacial.

Conforme relatado por SILVA \& CHAVES (2001), as linhas mais próximas apresentam alta variabilidade nos mapas bidimensionais, enquanto as mais distantes apresentam pouca variabilidade, como pode ser observado nas Figuras 2 e 3. A grande quantidade de cores nos mapas reflete que, apesar da dependência espacial encontrada, as perdas na planta e as totais pouco dependem do local amostrado, chegando quase ao efeito pepita. Essa alta variabilidade também 
tem sido observada em trabalhos de perdas na colheita de outras culturas, como no trabalho desenvolvido por SOUZA et al. (2005) que, analisando o efeito da variabilidade espacial de alguns fatores sobre as perdas de grãos durante o arranquio e o recolhimento do feijão, não encontraram dependência espacial das perdas, embora tenham apresentado elevada variação de seus valores na área.

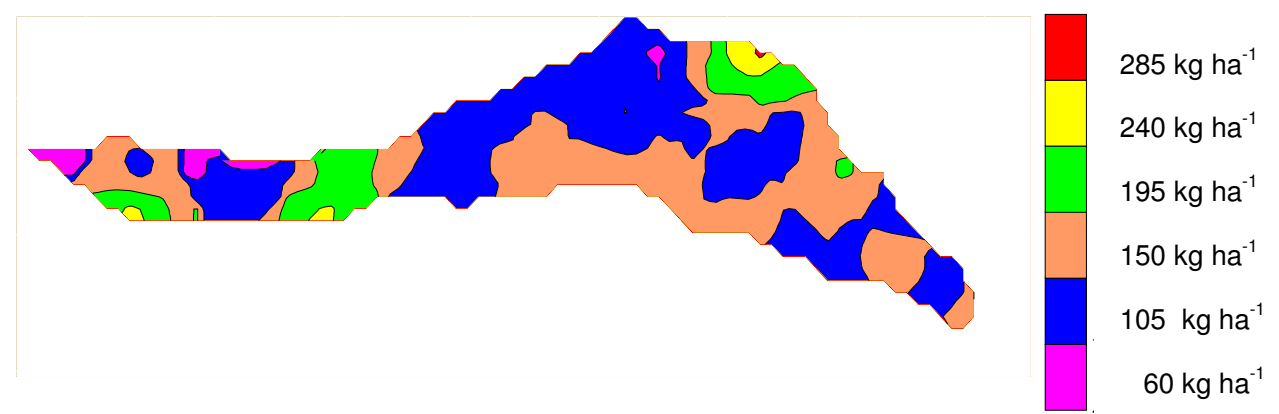

FIGURA 2. Distribuição espacial das perdas na planta na colheita mecanizada de algodão.

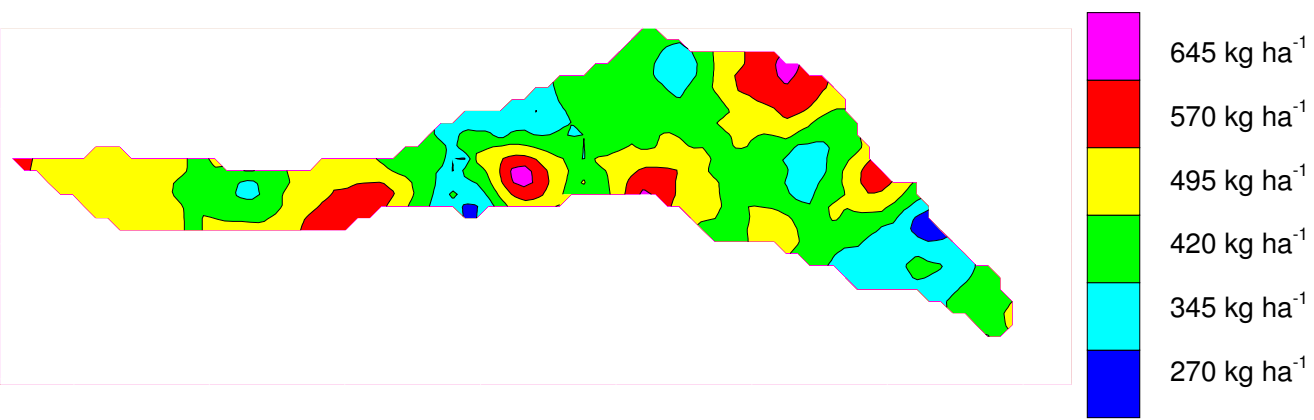

FIGURA 3. Distribuição espacial das perdas totais na colheita mecanizada de algodão.

Nas Figuras 4; 5 e 6, são apresentadas as cartas de controle da média para as perdas no solo, na planta e totais, respectivamente. Pode-se observar que todas as perdas avaliadas não estão sob controle, pois em todas existem pontos que ultrapassam os limites inferior e superior de controle.

Para as perdas no solo, constata-se que a maioria dos pontos amostrados está abaixo do LIC (15 pontos) e acima do LSC (16 pontos). A incidência de tantos pontos acima do LSC faz com que a média das perdas de algodão no solo seja mais elevada, atingindo valores superiores aos preconizados na bibliografia como ideais para a colheita de algodão em regiões de cerrado. Nesse enfoque, ao observar as cartas de controle como método de avaliar a colheita mecanizada, entendese que o controle de qualidade dessa operação precisa ser revisto, pois as perdas encontram-se bem acima do esperado, o que demonstra a baixa eficiência dessa operação, o que pode comprometer o lucro final de produção.

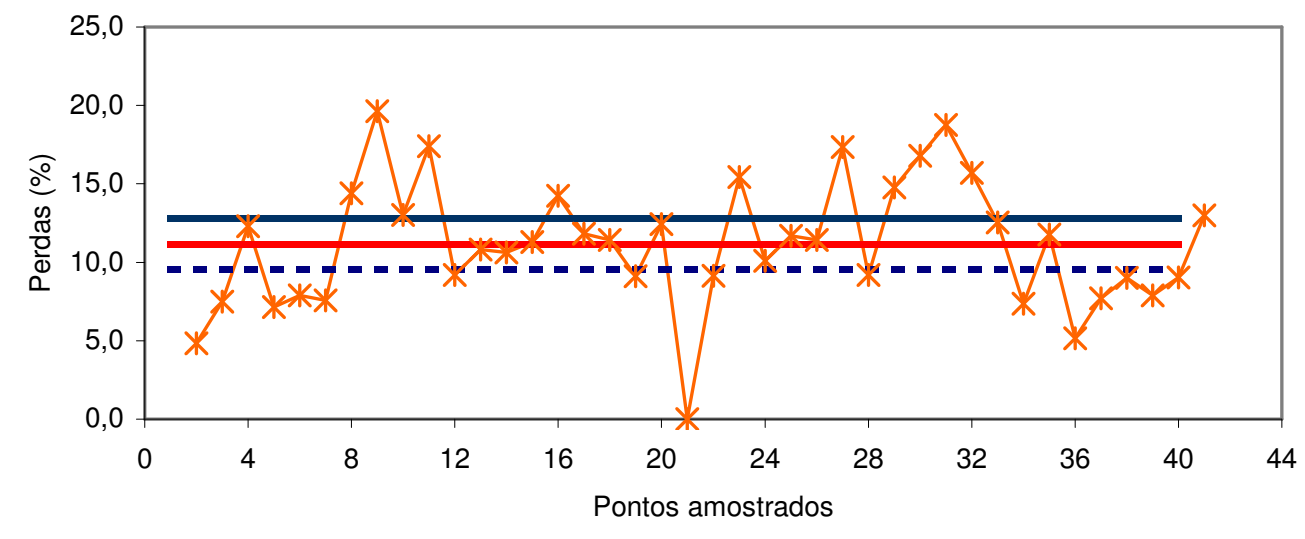

$$
\text { * PS - - - LIC - - LM - - LSC }
$$

FIGURA 4. Carta de controle para as perdas no solo, na colheita mecanizada de algodão. 


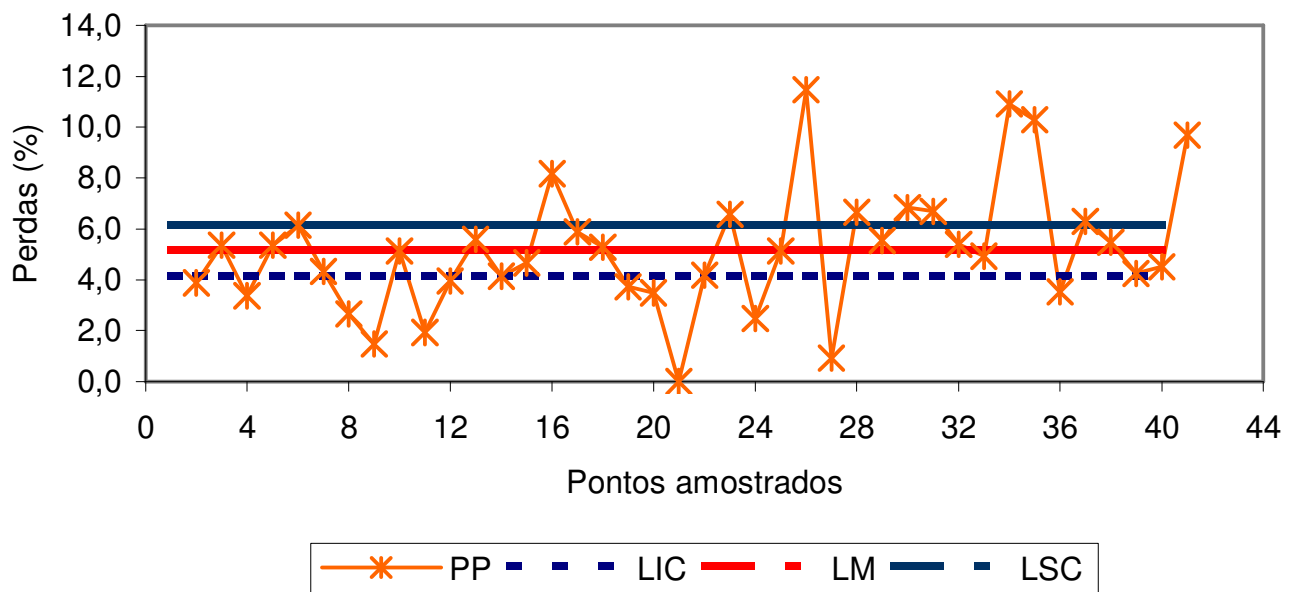

FIGURA 5. Carta de controle para as perdas na planta, na colheita mecanizada de algodão.

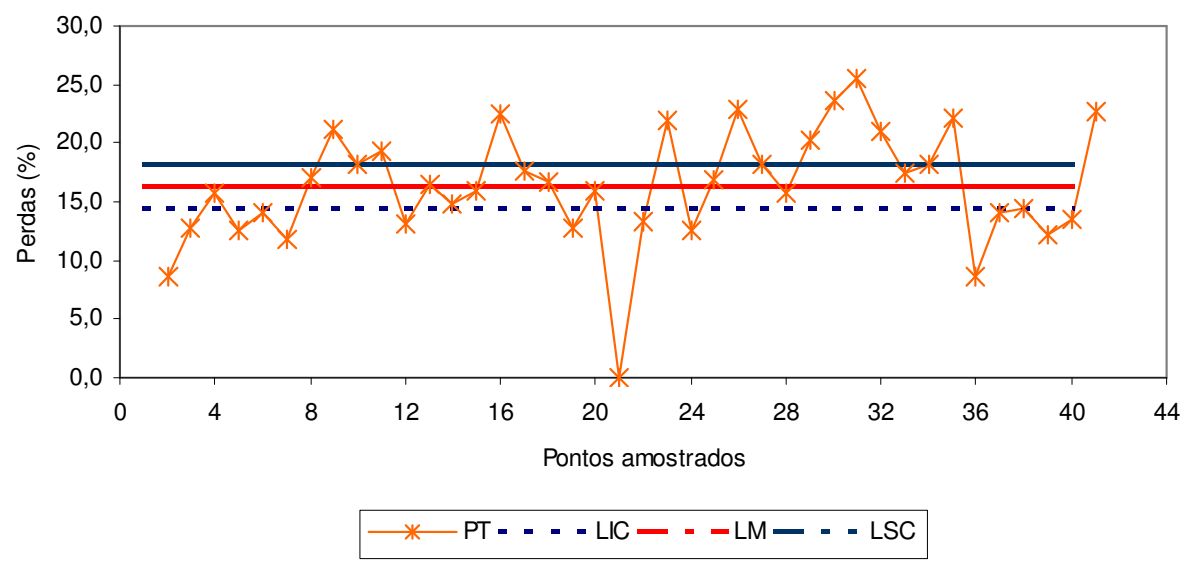

FIGURA 6. Carta de controle para as perdas totais, na colheita mecanizada.

\section{CONCLUSÕES}

As perdas encontradas na colheita mecanizada do algodão foram muito altas, encontrando-se muito superiores ao preconizado na bibliografia para a colheita de algodão em regiões de cerrado.

As perdas no solo não apresentaram dependência espacial, enquanto as perdas nas plantas e as totais ocasionaram dependência espacial moderada e forte, respectivamente.

Houve grande variabilidade espacial para as perdas no solo, na planta e para as totais.

Considerando-se o indicador perdas na colheita, o processo de colheita de algodão avaliado não se encontra dentro dos padrões de qualidade, sob o ponto de vista de controle estatístico de processo.

\section{REFERÊNCIAS}

BONILLA, J.A. Qualidade total na agricultura: fundamentos e aplicações. 2.ed. Belo Horizonte: Centro de Estudos de Qualidade Total na Agricultura, 1994. 344 p.

BRUNETA, E. Estratégias de colheita e beneficiamento para fibra de alta qualidade. In:

CONGRESSO BRASILEIRO DE ALGODÃO, 5., 2005, Salvador. Anais... Campina Grande: Embrapa-CNPA, 2005. 1 CD-ROM.

CAMARGO, E.C.G. Geoestatística: fundamentos e aplicações. In: Geoprocessamento em projetos ambientais. Disponível em: http://www.dpi.inpe.br/gilberto/tutoriais/gis_ambiente/5geoest.pdf. Acesso em: 10 out. 2007. 
CAMPOS, M.A.O.; SILVA, R.P.; MESQUITA, H.C.B.; ZABANI, S. Perdas na colheita mecanizada de soja no Estado de Minas Gerais. Engenharia Agrícola, Jaboticabal, v.25, n.1, p.207$13,2005$.

EGUCHI, E.S.; SILVA, E.L.; OLIVEIRA, M.S. Variabilidade espacial da textura e da densidade de partículas em um solo aluvial no município de Lavras - MG. Revista Brasileira de Engenharia Agrícola e Ambiental, Campina Grande, v.6, n.2, p.242-6, 2002.

ELEUTÉRIO, J.R. Colheita mecânica: avaliação das perdas e otimização. In: CONGRESSO BRASILEIRO DE ALGODÃO, 3., 2001, Campo Grande. Anais...Campina Grande: EMBRAPA/ CNPA, 2001, p.11-14.

EMBRAPA. EMPRESA BRASILEIRA DE PESQUISA AGROPECUÁRIA. Algodão: Tecnologia de produção. Dourados: Embrapa Agropecuária Oeste/Embrapa Algodão, 2001. 296 p.

EMBRAPA. EMPRESA BRASILEIRA DE PESQUISA AGROPECUÁRIA. Colheita. Disponível em: <http://sistemasdeproduçao.cnptia.embrapa.br/FontesHTML/Algodao/AlgodaoCerrado/ colheita.htm> Acesso em: 10 out. 2006.

FREDDI, O.S. Variabilidade espacial da produtividade do feijão (Phaseolus vulgaris L.) e de atributos químicos de um Latossolo Vermelho distroférrico de Selvíria (MS) sob preparo convencional e plantio direto. 2003. 154 f. Dissertação (Mestrado em Sistema de Produção) Universidade Estadual Paulista, Faculdade de Engenharia de Ilha Solteira, 2003.

FREIRE, E.C.; BOLDT, A.F.; OLIVEIRA, L.C.; ANDRADE, F.P. Perdas na colheita mecanizada do algodão em Mato Grosso. In: REUNIÃO NACIONAL DO ALGODÃO, 8., 1995, Londrina. Atas... Londrina: IAPAR, 1995. p.133.

GUIMARÃES, E.C. Geoestatística básica e aplicada. Uberlândia: UFU, 2001. 48 p. (Publicação Didática).

KUME, H. Métodos estatísticos para melhoria da qualidade. 4.ed. São Paulo: Gente, 1993. 245 p.

LANDIM, P.M.P. Análise estatística de dados geológicos. São Paulo: Fundação Editora da UNESP, 1998. 226 p. (Ciência e Tecnologia).

MELLO, C.M.; CATANEO, A. Variabilidade espacial de atributos químicos de um Nitossolo Vermelho distrófico de Botucatu - SP. Energia na Agricultura, Botucatu, v.16, n.4, p.37-44, 2001.

MESQUITA, C.M.; COSTA, N.P.; PEREIRA, J.E. ; MAURINA, A.C.; ANDRADE, J.G. Perfil da colheita mecânica da soja no Brasil: perdas e qualidades físicas do grão relacionadas à características operacionais. In: CONGRESSO BRASILEIRO DE ENGENHARIA AGRÍCOLA, 30., 2001, Foz do Iguaçu. Anais... Cascavel: Sociedade Brasileira de Engenharia Agrícola, 2001. 1 CD-ROM.

MILAN, M. Controle de qualidade em operações agrícolas. Notesalq, Piracicaba, v.5, n.11, p.4-5, 1997.

MONTGOMERY, D.C. Introduction to statistical quality control. 5.ed. New York: John Wiley, 1985. 489 p.

NOGUEIRA, L.S.; SILVA, V.R. Avaliação de perdas na colheita mecanizada do algodoeiro no Mato Grosso. In: REUNIÃO NACIONAL DO ALGODÃO, 1993, Cuiabá. Atas... EMPAERMT/EMBRAPA-CNPA, 1993. p.199.

OOSTERHUIS, D.M. Growth and development of a cotton plant. In: CIA, E.; FREIRE, E.C.; SANTOS, W. J. dos. Cultura do algodoeiro. Piracicaba: POTAFOS, 1999. p.35-55.

RIBEIRO JÚNIOR, P.J. Métodos geoestatísticos no estudo da variabilidade espacial de parâmetros de solo. 1995.99 f. Dissertação (Mestrado em Estatística e Experimentação Agronômica) - Escola Superior de Agricultura "Luiz de Queiroz", Universidade de São Paulo, Piracicaba, 1995. 
ROBERTSON, G.P. $G S^{+}$: Geoestatistics for the enviromental sciences. Michigan: Gamma Design Software Plainwell, 1998. 152 p.

SILVA, P.C.M.; CHAVES, L.H.G. Avaliação e variabilidade espacial de fósforo, potássio e matéria orgânica em Alissolos. Revista Brasileira de Engenharia Agrícola e Ambiental, Campina Grande, v.5, n.3, p. 431-6, 2001.

SOUZA, C.M.A.; YAMAMOTO, N.T.; QUEIROZ, D.M.; ALVES, L.A. Geoespacialização das perdas quantitativas de grãos na colheita de feijão usando uma colhedora de arrasto. In: SIMPÓSIO INTERNACIONAL DE AGRICULTURA DE PRECISÃO, 3., 2005, Sete Lagoas. Anais... Sete Lagoas: Embrapa Milho e Sorgo, 2005. 1 CD-ROM.

VIEIRA, S.R. Geoestatística em estudos de variabilidade espacial do solo. In: NOVAIS, R.F.; ALVAREZ V. V.H.; SCHAEFER, G.R. Eds. Tópicos em ciência do solo. Viçosa: Sociedade Brasileira de Ciência do Solo, 2000. v.1, p.1-54.

VIEIRA, C.P.; CUNHA, L.J.C.; ZÓFOLI, R.C. Colheita. In: Algodão: Tecnologia de Produção. Dourados: Embrapa Agropecuária Oeste, 2001. p.273-6.

VIEIRA, S.R.; MILLETE, J.; TOPP, G.C.; REYNOLDS, W.D. Handbook for geoestatical analysis of variability in soil and climate data. In: ALVAREZ V.V.H.; SCHAEFER, C.E.G.R.; BARROS, N.F.; MELLO, J.W.V.; COSTA, L.M. (Eds.) Tópicos em ciência do solo. Viçosa: Sociedade Brasileira de Ciência do Solo, 2002. v.2, p.1-45.

WARRICK, A.W.; NIELSEN, D.R. Spatial variability of soil physical properties in the field. New York: Academic Press, 1980. p.319-44.

WEBSTER, R.; OLIVER, M.A. Sample adequately to estimate variograms of soil properties. Journal of Soil Science, Oxford, v.43, p.177-92, 1992.

WOLLENHAUPT, N.C.; MULLA, D.J.; CRAWFORD, G. Soil sampling and interpolation techniques for mapping spatial variability of soil properties. In: PIERCE, F.J.; SADLER, E.J. The state of site-specific management for agriculture. Madison, 1997. p.19-53. 